\title{
ACORDOS DE INVESTIMENTO E A DIFUSÃO DAS IDEIAS DE RESPONSABILIDADE SOCIAL CORPORATIVA: APONTAMENTOS CRÍTICOS A PARTIR DO MODELO BRASILEIRO
}

Marina Sanches Wünsch

Fábio Costa Morosini²

\begin{abstract}
SINOPSE
Este artigo visa analisar a inserção da cláusula de responsabilidade social corporativa (RSC), enquanto instrumento de proteção de direitos humanos, nos tratados bilaterais de investimento (TBIs); e explorar se os Acordos de Cooperação e Facilitação de Investimentos (ACFIs) brasileiros oferecem avanços sobre o tema. Nesse sentido, o texto examina a difusão do movimento de RSC e sua relação com o paradigma neoliberal e expõe as lacunas existentes no atual marco regulatório sobre empresas e direitos humanos. Por fim, o estudo propõe caminhos pelos quais é possivel avançar na responsabilização das empresas transnacionais, dentro e fora dos TBls.
\end{abstract}

Palavras-chave: direitos humanos; responsabilidade social corporativa; empresas transnacionais; tratados bilaterais de investimento.

\begin{abstract}
This article intends to analyze the inclusion of corporate social responsibility (CSR) clauses, as an instrument for the protection of human rights, in bilateral investment treaties (BITs); and to explore whether the Brazilian Agreements on Investment Cooperation and Facilitation (Acordos de Cooperação e Facilitação de Investimentos - AICFs) sheds new light to the ongoing debate. Accordingly, the paper deals with the diffusion of the CSR movement and its relationship with the neoliberal paradigm and presents the gaps in the current regulatory framework on business and human rights. Finally, the paper proposes ways in which it is possible to advance for an enforceable model of accountability for transnational corporations, both inside and outside the BITs.
\end{abstract}

Keywords: human rights; corporate social responsibility; transnational corporations; bilateral investment treaties.

JEL: F21; F23; K38; M14; N4.

Artigo recebido em 8/3/2021 e aprovado em 30/3/2021.

DOl: http://dx.doi.org/10.38116/bepi29art9

\section{INTRODUÇÃO}

A responsabilidade social corporativa (RSC) de atores estrangeiros (investidores e empresas, por exemplo) tem sido um tema crítico nas últimas décadas, repercutindo nos debates sobre neoliberalismo, desenvolvimentismo e defensores de direitos humanos (DHs). Este artigo pretende discutir a inserção de cláusulas de RSC nos tratados bilaterais de investimento (TBIs) e seu papel na proteção de DHs.

1. Professora da Universidade Federal do Pampa (Unipampa); e doutora em estudos estratégicos internacionais pela Universidade Federal do Rio Grande do Sul (UFRGS), com bolsa de estudos da Coordenação de Aperfeiçoamento de Pessoal de Nível Superior (Capes). E-mail:<marinawunschs@gmail.com>.

2. Professor associado da Faculdade de Direito da UFRGS, onde coordena o Centro para Direito, Globalização e Desenvolvimento. E-mail:<fabio.morosini@ufrgs.br>. 
Além disso, pretende analisar se os Acordos de Cooperação e Facilitação de Investimentos (ACFIs) brasileiros oferecem avanços sobre o tema.

A atuação das empresas transnacionais ${ }^{3}$ (ETNs) ocorre por meio do investimento estrangeiro direto (IED) e os TBIs se popularizaram como mecanismo de regulação estatal desses investimentos. Entretanto, entre 1950 e 1990, esses tratados refletiam uma maior preocupação em proteger os investidores, uma vez que os fluxos de investimento tendiam a ser unidirecionais, no sentido Norte-Sul. Já a preocupação com a proteção dos $\mathrm{DH}$ s concentrou-se quase exclusivamente no regime internacional dos $\mathrm{DH}$, que enfrenta dificuldades para impor sua efetividade, especialmente diante das violaçóes cometidas por ETNs.

A partir dos anos 1980, com a redução do papel do Estado e diante de um processo de desregulação, houve o crescimento da influência das ETNs. Tal ambiente criou as condiçôes para um movimento de autorregulação da atuação das ETNs por meio de mecanismos de RSC. Este artigo busca evidenciar a intrínseca relaçáo entre o surgimento do movimento de RSC e o neoliberalismo, ${ }^{4}$ ainda nos anos 1980.

Atualmente, a inserção de cláusulas de RSC objetiva inserir a agenda de DHs nos TBIs. Todavia, surgem questionamentos acerca de cláusulas de proteção de $\mathrm{DHs}$ que possam ir além de mecanismos voluntários (soft law) e assegurem efetivamente a proteção dos $\mathrm{DH}$ da população impactada pelos investimentos. Tais questionamentos decorrem do contexto neoliberal em que está inserido o movimento de RSC, que sugere um processo de desregulaçáo pelo Estado e de autorregulaçáo da atuação de atores privados por meio de mecanismos voluntários.

O artigo está assim estruturado: inicialmente, busca-se contextualizar a origem da RSC e sua relação com a regulação internacional das ETNs. Em seguida, diante do avanço do movimento de RSC, analisa-se a sua inserção nos acordos de investimento tradicionais, bem como discute-se o modelo brasileiro de acordo, o ACFI, enquanto alternativa proveniente de um país em desenvolvimento. Finalmente, o artigo encaminha propostas a fim de avançar na discussão acerca das cláusulas de RSC em acordos de investimento enquanto um novo mecanismo de proteção dos DHs.

3. A expressão transnacional foi consagrada pela Organização das Nações Unidas (ONU). ETNs são definidas como empresas que atuam além e através das fronteiras estatais (em inglês, transnational corporations - TNCs). 0 termo é considerado por parte da doutrina como mais correto, porque o qualificativo "multinacional" pode conduzir a equívoco, uma vez que essas empresas não têm muitas nacionalidades. Neste artigo, a palavra multinacionais será utilizada apenas para manter a forma original usada pelo autor de referência ou o correspondente período histórico.

4. 0 neoliberalismo não é um único conceito ou modelo, porém seu marco teórico pode ser claramente identificado. A doutrina neoliberal surge em oposição às teorias do Estado intervencionista, como as de John M. Keynes, e obteve respeitabilidade acadêmica quando Friedrich Hayek, em 1974, e Milton Friedman, em 1976, ganharam o Prêmio Nobel de Economia. Ademais, passou a ter grande influência com a adoção de políticas econômicas de cunho neoliberal pelos governos Thatcher (1979), na Inglaterra, e Reagan (1980), nos Estados Unidos, entre outros. Hall (2011), em seu artigo The Neoliberal Revolution: Thatcher, Blair, Cameron - the long march of neoliberalism continues, define 0 modelo neoliberal tanto como a ausência do governo do Estado sobre os indivíduos livres e sua propriedade privada quanto como economia de livre mercado, ou seja, ausência de intervenção do Estado na economia, especialmente quanto a regulações estatais, com prevalência dos interesses corporativos e privados (op. cit., p. 10-11). 


\section{CONTEXTUALIZAÇÃO DA RSC}

\subsection{A regulação das ETNs e os DHs}

O sistema internacional de proteção aos DHs é centrado no Estado, ou seja, está baseado na obrigação dos Estados em proteger os DHs. Logo, os mecanismos de coerção e responsabilização são direcionados aos Estados como parte dos tratados internacionais sobre o tema. Ocorre que, nas últimas décadas, os Estados deixaram de ter, no plano internacional, o monopólio das acusaçóes de agente violador de $\mathrm{DH}$ s, enquanto tem crescido o número de denúncias contra ETNs por violaçóes desse tipo.

Um dos primeiros casos a atrair grande atenção internacional e a ser levado a um tribunal foi o do dramaturgo e ativista de DHs nigeriano Ken Saro-Wiwa, em $1995 .{ }^{5}$ Ele é visto como o ponto de inflexão para o desencadeamento do debate sobre empresas e DHs, que é crescente no âmbito das organizaçóes internacionais.

Cabe ressaltar, entretanto, que debates entre países hospedeiros de IED e ETNs já haviam sido travados na ONU ainda nos anos 1960 e 1970, ligados a temas como regimes de propriedade mineral e a soberania dos Estados $^{6}$ (Busturia, 2015, p. 197-198). Além da ONU, no mesmo período, outras iniciativas partiram da Organização Internacional do Trabalho (OIT), com a Declaraçáo Tripartite de Princípios sobre Empresas Multinacionais e Política Social, de 1977; e da Organização para a Cooperação e o Desenvolvimento Econômico (OCDE), com as Diretrizes para Empresas Multinacionais, de 1976, acordadas por dez países-membros como parte da Declaração sobre o Investimento Internacional e as Empresas Multinacionais.

As diretrizes da OCDE são recomendações voluntárias para as ETNs referentes a questôes como emprego, relações industriais, ética, DHs, meio ambiente, corrupçáo etc. Para Bustura (2015, p. 119-121), essas diretrizes são um marco importante do desenvolvimento e do impulsionamento da RSC e resultam da crescente pressão das ETNs na ONU para evitar a adoção de um código de conduta vinculante. Essa pressão esvaziou o espaço criado na ONU para a regulação das ETNs, transferindo o processo para outras organizaçôes internacionais mais alinhadas aos interesses empresariais.

As primeiras iniciativas de regular as ETNs ocorreram, portanto, nos anos 1970. Já entre os anos 1980 e 2000, tais iniciativas no plano internacional ficaram estagnadas. No entanto, a assinatura do Pacto Global, em 2000, marca o retorno do debate sobre a responsabilidade das empresas no âmbito da ONU.

Outro marco importante ocorreu em 2005, por meio da Resolução no 2005/1969, que criou um mandato de representante especial do secretário-geral (special representative of the secretary-general -

5. 0 chamado caso Wiwa envolveu as empresas Royal Dutch Petroleum e Shell Transport and Trading por meio de sua subsidiária Shell Petroleum Development Company (SPDC) da Nigéria, joint venture criada para a exploração e a extração de petróleo no delta do rio Níger. Ken Saro-Wiwa participava do Movimento pela Sobrevivência do Povo Ogoni (Mosop), que reivindicava a sobrevivência do povo indígena ogoni, opunha-se ao governo nigeriano e protestava ativamente contra o modo como a Shell Nigéria conduzia suas atividades na região (Martín-Ortega, 2008, p. 72-73).

6. Em 1962, países em desenvolvimento levaram à Assembleia Geral da ONU a discussão relativa à soberania dos Estados sobre seus recursos naturais. 0 resultado foi a Resolução no 1.803 da XVII Assembleia Geral, de 14 de dezembro de 1962, a respeito da "soberania permanente sobre os recursos naturais". A independência das antigas colônias na África e na Ásia e as denúncias sobre a relação das ETNs com regimes militares na América Latina também contribuíram para impulsionar o debate sobre a necessidade de regulação das ETNs no interior de organizações não governamentais (ONGs), levando, inclusive, à discussão sobre a elaboração de um código de conduta internacional em 1975 (Frieden, 2008). 
SRSG) da ONU sobre empresas e DHs, sendo responsável pela elaboração dos Princípios Orientadores da ONU sobre Empresas e Direitos Humanos, os quais foram aprovados em 2011 por consenso pelo Conselho de Direitos Humanos. Esses princípios constituem o principal documento na área até hoje. 7

Todavia, apesar das diversas iniciativas para regular as ETNs, até o momento nenhum instrumento regulatório é juridicamente vinculativo ou cria obrigaçóes diretas para as empresas. Ainda recai sobre os Estados assegurar a proteção dos $\mathrm{DHs}$ e, portanto, monitorar, fiscalizar e responsabilizar as ETNs em caso de descumprimento das obrigaçóes de DHs.

Em contrapartida, a partir dos anos 1980, com a difusão do ideário neoliberal, o que se observa é uma tendência à desregulamentação da atividade privada por parte do Estado e de diminuição da proteção dos $\mathrm{DH}$ s, com o fim de atrair investimentos. As ETNs, por sua vez, passaram a adotar medidas de automonitoramento, por meio da RSC. Como resultado, as organizaçóes internacionais começaram a ocupar a agenda de regulação da atuação das transnacionais apoiando-se em marcos normativos de lógica voluntarista, ao mesmo tempo que reforçam a RSC.

O problema, assim posto, não está na centralidade do Estado na proteção dos DHs, mas na adoção de políticas neoliberais, que revisaram o papel deste e transferiram para as ETNs a capacidade de autorregulagem por meio da RSC, como abordado a seguir.

\subsection{A origem neoliberal da RSC}

A origem e a consolidação do movimento de RSC a partir dos anos 1980 estão relacionadas a fatores como: i) a difusáo de uma agenda neoliberal e a consequente desregulaçáo da atividade privada pelo Estado; ii) a necessidade de legitimação das ETNs, diante desse fenômeno; iii) a crescente discussão sobre RSC no meio acadêmico, com a adesão de empresas; e iv) o surgimento de diversas organizaçóes de RSC, a fim de validar tais dimensóes práticas.

Para compreender a relação entre a RSC e a agenda neoliberal, é necessário entender primeiramente o próprio modelo neoliberal. Em sua agenda, há a defesa e a disseminação da ideia de eficiência estatal. A partir dessa lógica, o Estado deve agir como se empresa privada fosse, o que justificaria a busca pela redução de custos. Sua tradicional função de proteçáo social passa a ser negligenciada por meio da redução de suas políticas sociais (Brown, 2009, p. 39-40).

Dentro do escopo do projeto neoliberal, a partir dos anos 1980, promoveram-se a abertura comercial e financeira, a privatização de empresas estatais, a desregulamentação das relações de trabalho e a compressão do padrão de proteção social. Tais medidas contribuíram para que parcela da população passasse a questionar a atuaçáo das empresas, uma vez que a retirada de determinadas garantias sociais prejudicou os cidadáos enquanto as favorecia.

Entre as políticas adotadas pelo governo Thatcher a partir de 1979, estáo, por exemplo: i) o desmantelamento dos movimentos sindicalistas britânicos por meio da restrição de sua atuação e da imposição de sançôes; ii) a remoção da exigência de dedução de contribuiçóes sindicais dos empregados, contando para isso com o apoio de grande parte da imprensa para colocar a opiniáo pública contra os sindicatos; iii) a desregulamentação do mercado financeiro, o que possibilitou a criaçáo de um mercado mais complexo; e iv) privatizaçóes - entre 1982 e 1986, foram desestatizadas 
mais de 22 empresas, incluindo companhias aéreas, de telecomunicação e petrolíferas (Kinderman, 2012). Além disso, houve mudanças em políticas sociais, como nas áreas de saúde e de educação.

Não por acaso, os movimentos de RSC surgem justamente nos países em que as políticas neoliberais foram implementadas de maneira mais profunda, como Reino Unido e Estados Unidos. Logo, a RSC surge para compensar a ausência institucional do Estado e, ao mesmo tempo, legitimar a atuação das empresas, uma vez que, diante da sociedade, elas não representam o bem-estar coletivo ${ }^{8}$ (Tsutsui e Lim, 2015, p. 41). Segundo Kinderman (2012, p. 3, tradução nossa), "a RSC tem servido para legitimar as reformas neoliberais ex ante, bem como para responder ex post às pressóes geradas pela liberalização e por um ambiente neoliberal".

Entre 1980 e 2000, as iniciativas dos Estados em regular as ETNs por meio de tratados ficaram estagnadas, ainda que alguns instrumentos voluntários já existissem. Diante da inércia dos Estados, surge a discussão sobre RSC em meio ao ambiente empresarial e, principalmente, dentro do meio acadêmico, ganhando cada vez mais relevância entre economistas e administradores (Carroll, 1999, p. 269).${ }^{10}$ Com o avanço da discussão sobre RSC, em 2000, a ONU apresentou o Pacto Global, ${ }^{11}$ que é claramente uma assimilação, pela organização, do movimento de RSC e se utiliza da própria lógica de RSC, qual seja, regras voluntárias, formuladas pelas próprias empresas, divulgadas por códigos de conduta e relatórios.

No espaço acadêmico, os conceitos de RSC, desenvolvidos especialmente nos anos 1980, aparecem com o discurso de que as empresas, além de buscar o lucro, devem promover o bem-estar social; de que os negócios devem tornar-se responsáveis perante a sociedade; e de que é preciso contribuir para o avanço da sociedade, sendo-lhes, portanto, uma estratégia adequada. Além disso, estudos que buscavam estabelecer a relação entre reputação e performance financeira também passaram a interessar aos estudiosos (Carroll, 1999).

Entre os autores, entretanto, era bastante difícil chegar a um consenso sobre o que seria um comportamento socialmente responsável. A unanimidade, de fato, existia em torno da ideia de que a RSC ia além das obrigaçôes legais e, assim, deveria ser voluntária.

8. Lembrando que, nesse mesmo sentido, os escândalos envolvendo as empresas deixam de ser direcionados aos Estados, e a responsabilidade passa a ser ligada diretamente às empresas (Tsutsui e Lim, 2015, p. 40). Podemos citar, como exemplo, o caso do desastre químico ocorrido em 3 de dezembro de 1984 na cidade de Bhopal, estado de Madhya Pradesh, na Índia. Na ocasião, cerca de 45 t do perigoso gás isocianato de metila escaparam de uma fábrica de inseticidas na propriedade da subsidiária indiana da empresa americana Union Carbide, matando milhares de pessoas imediatamente. Investigações estabeleceram que os procedimentos operacionais e de segurança abaixo do padrão na planta com falta de pessoal levaram à catástrofe. Disponível em: <https://bit.ly/3hcFnhR>.

9. "CSR has served to legitimate neo-liberal reforms ex ante, as well as responding ex post to the pressures generated by liberalization and by a neo-liberal environment."

10. Muitos autores citam a publicação do livro The Social Responsibilities of the Businessman pelo economista americano Howard R. Bowen, em 1953, como sendo o marco inicial da literatura moderna sobre RSC. Não obstante, a literatura sobre o tema à época era escassa e a responsabilidade era focada na figura do empresário e na ideia de que decisões e ações empresariais poderiam afetar a vida dos cidadãos de diferentes formas (Carroll, 1999, p. 269).

11. 0 pacto é uma iniciativa voluntária, desenvolvida pelo ex-secretário-geral da ONU Kofi Annan, a fim de mobilizar a comunidade empresarial internacional para comprometer-se em alinhar suas operações com dez princípios sobre DHs, trabalho, meio ambiente e luta contra a corrupção. 0 pacto conta com milhares de empresas de diferentes setores e instituiu uma regra que determina que somente podem continuar fazendo parte da rede como membros aqueles que enviarem relatórios anuais informando sobre o seu progresso na implementação dos princípios básicos do pacto. Disponível em: <http://pactoglobal.org.br/o-que-e/>. 


\section{GRÁFICO 1}

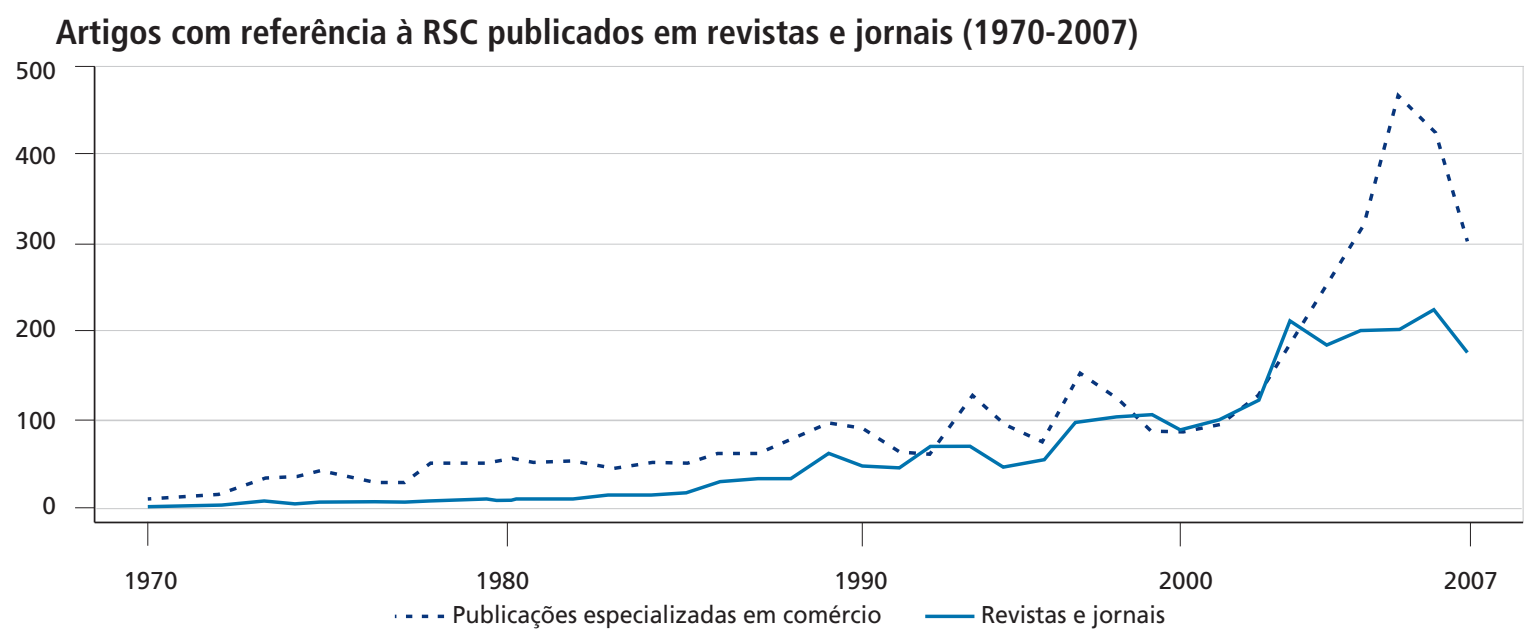

Fonte: Tsutsui e Lim (2015, p. 45).

No período em questão, também foram criadas as primeiras organizaçôes de RSC. Tsutsui e Lim (2015, p. 45) citam como exemplos a Coalition of Environmentally Responsible Companies (1989), a Business for Social Responsibility (1992) e o Boston College Center for Corporate Citizenship (1985), com destaque em âmbito internacional para o International Business Leaders Forum (1990), o World Economic Forum (1987) e o World Business Council for Sustainable Development (1995). Outro exemplo é a Business in the Community (BITC), organizaçáo líder em RSC no Reino Unido, fundada em 1982 (Kinderman, 2012, p. 7). Todas elas são organizaçôes sem fins lucrativos, que contam com a participação de empresas privadas para desenvolver as ideias de RSC - o que, portanto, sustenta o argumento de que o avanço da RSC está associado ao avanço do neoliberalismo. A título de exemplo, cabe lembrar que umas das principais medidas neoliberais adotadas pelo governo Thatcher foi a privatização de empresas estatais. Essas empresas recém-privatizadas, por sua vez, logo se tornaram membros da BITC a fim de demonstrar que ainda existia uma preocupação social, já que o Estado estava preocupado em criar um sistema de regulação privado. Desse modo, "a RSC ajudou a legitimar as empresas há pouco privatizadas e a compensar a repercussão decorrente das demissóes em larga escala" ${ }^{12}$ (Kinderman, 2012, p. 15, tradução nossa).

A institucionalização da RSC passou a ser vista de forma positiva pela sociedade. Muitos movimentos sociais, apesar de criticarem a atuação das empresas, não criticavam diretamente a RSC, já que esta adquiriu uma imagem positiva, qual seja: contribuir para uma mudança no comportamento das companhias. E, por meio do Pacto Global, a própria ONU se torna o locus de divulgação das empresas que pretendem ser reconhecidas como socialmente responsáveis.

Em síntese, percebe-se que a RSC não decorre de uma ameaça de regulação das ETNs por parte do Estado. Pelo contrário, as regulaçóes que restringem o livre comércio, tanto local quanto a nível internacional, ${ }^{13}$ foram diminuindo, e a RSC surge, entáo, para compensar essa ausência institucional

12. "CRS has helped to legitimate newly privatized companies and compensate for the fall out arising from large-scale layoffs."

13. As iniciativas que buscavam regular as ETNs são deixadas de lado, sendo a última a da OIT, em 1977. No nível local, o Estado também passa por um processo de desregulação. Esse cenário cria um ambiente favorável ao comércio internacional e ao IED, que passa a ser cada vez mais cotejado por meio de TBls. 
do Estado, ao mesmo tempo que legitima a atuação das empresas junto à sociedade, com impacto sobre seu valor de mercado.

\section{OS ACORDOS DE INVESTIMENTO E A INSERÇÃO DA RSC}

O desenvolvimento do regime internacional de investimentos não ficou circunscrito às iniciativas multilaterais que visavam controlar as atividades das ETNs. De fato, tal regime é atualmente governado, sobretudo, por meio de TBIs ou de acordos mais abrangentes que contêm cláusulas sobre investimentos. Por isso, a inserção de cláusulas de RSC em acordos de investimento tende a ser vista de forma positiva, já que preencheria uma lacuna antiga referente à criaçáo de um instrumento internacional multilateral vinculante que regule a atuação das ETNs, unindo o regime de investimento ao dos DHs.

Contudo, pretende-se neste artigo desafiar o argumento de que a inclusão de cláusulas de RSC em TBIs, tout court, assegura a proteção efetiva de DHs. Para tanto, na sequência, são apresentadas duas análises: a primeira acerca dos modelos tradicionais de acordos de investimento e a segunda sobre o modelo brasileiro, o ACFI.

\subsection{As cláusulas de RSC nos acordos de investimento}

Entre 1959 - ano do primeiro tratado - e 1991, mais de quatrocentos TBIs foram assinados no mundo (Guzman, 1998, p. 652). A ampla maioria desses TBIs envolvia um país desenvolvido e um em desenvolvimento, com a principal finalidade de proteger o investidor. Todos os países desenvolvidos, assim como mais de noventa países entáo classificados como em desenvolvimento, faziam parte de pelo menos um TBI.

Os modelos dos TBIs são estabelecidos, normalmente, pelos países desenvolvidos. Segundo Guzman (1998, p. 660), a submissão dos países em desenvolvimento aos TBIs precisa ser compreendida dentro de um contexto de ausência, no direito internacional, de mecanismos que ofereçam proteção ao investimento perante o Estado receptor. Tal ausência afeta o poder de barganha dos Estados durante as negociaçóes, levando os países em desenvolvimento, desejosos em encorajar o ingresso de investimentos externos, a ceder a modelos propostos por países desenvolvidos exportadores líquidos de capital.

Como consequência, os instrumentos se restringem a regular o interesse dos investidores e não dialogam com outros instrumentos internacionais, especialmente, os instrumentos de DHs. Segundo Sornarajah (2010, p. 228, tradução nossa), DHs raramente são mencionados em TBIs, contudo,

os direitos humanos assumirão maior significado no futuro e, portanto, terão que ser acomodados nos tratados de investimento. A tendência das elites em muitos Estados voltada para o neoliberalismo tem sido atrair investimentos estrangeiros, mesmo à custa dos direitos humanos. ${ }^{14}$

Ao inserir cláusulas de RSC nos TBIs, o objetivo é incorporar mais obrigaçôes aos investidores a fim de incentivá-los a respeitar os DHs e as leis ambientais no Estado anfitrião. Todavia, simplesmente inserir cláusulas estabelecendo que os Estados incentivem as empresas que operam em seu território

14. "(...) human rights will assume greater significance in the future and will therefore have to be accommodated within investment treaties. The tendency of elites in many states geared to neo liberalism has been to attract foreign investment even at the cost of human rights." 
ou estão sujeitas à sua jurisdição a incorporar voluntariamente padróes de RSC em suas práticas e políticas internas, por si só, não apresenta avanços em termos de criação de obrigaçôes para as ETNs.

Embora essas disposiçóes ainda não tenham um padrão, sua aplicação baseia-se, em grande parte, na supervisão interna dos Estados. Não obstante, destaca-se sempre a utilização da linguagem voluntária com relação à conduta das empresas. Em outras palavras, o Estado deve incentivar as empresas a adotarem mecanismos de RSC; no entanto, a responsabilidade ainda é centrada na figura do Estado. Além disso, tais disposiçôes não trazem grandes inovaçôes - são uma reprodução do que já é proposto pelos outros instrumentos internacionais, como os Princípios Orientadores da ONU. ${ }^{15}$ Os princípios representam o fortalecimento da transferência do controle político, ou de regulaçáo, para agentes privados como as ETNs por meio da RSC.

Os conceitos de RSC, por sua vez, baseiam-se fundamentalmente em duas premissas:

- o dever das ETNs é cumprir as obrigaçóes legais (que, dentro do recorte neoliberal, devem ser mínimas e, portanto, não devem intervir na atuação do setor privado); e

- as ETNs, por motivos éticos e de forma voluntária, buscam se comprometer em promover o bem-estar (papel tradicionalmente atribuído ao Estado) nos países em que atuam.

Nesse sentido, a política social é voluntária, e não um direito; é focalizada, e não universal; e reforça a sua presença, mas não é vinculante.

Além do mais, a voluntariedade explica o motivo pelo qual existe uma tendência em excluir tais cláusulas de arbitragens, seja investidor-Estado, seja Estado-Estado, reforçando o caráter de automonitoramento da RSC. Nesse sentido, a partir de uma perspectiva neoliberal, o Estado, especialmente em economias exportadoras de capital, reluta em adotar medidas e legislaçóes que limitem a atuação das empresas ou as prejudiquem na "competição internacional", principalmente no que tange a regras de proteçáo de DHs. Assim, esse Estado tende a favorecer uma abordagem "voluntária” e "privada" de RSC, como a presente nos TBIs.

Segundo Backer (2015, p. 64, traduçáo nossa), "os direitos humanos tornaram-se parte do discurso do mercado privado, bem como do sistema estatal". ${ }^{16} \mathrm{O}$ Estado se exime do ônus de regular, enquanto a empresa assume esse papel, ao mesmo tempo que invoca a RSC como uma forma de obter uma imagem positiva junto à sociedade. Para as corporaçóes, reputação da marca e imagem importam, e toda uma indústria profissional surgiu para atender à necessidade de protegê-las e preservá-las, pois é inegável que essa nova maneira de relacionar-se com a sociedade, à medida que abre novos mercados e incrementa o número de investidores, maximiza o valor da companhia.

As empresas buscam firmar essa imagem positiva por meio de documentos que tornam públicos seus valores, suas políticas e suas práticas de RSC, a exemplo dos códigos de conduta. A realidade, no entanto, revela que a RSC tende a não sair do papel, no sentido de que poucas empresas demonstram submeter suas atividades a mecanismos efetivos de monitoramento ou tomar medidas corretivas em casos de violação dos DHs.

15. Esses princípios baseiam-se em duas premissas: i) o Estado é o principal responsável pela proteção internacional dos DHs; e ii) em decorrência da responsabilidade corporativa, as ETNs têm a obrigação de respeitar os DHs e devem, portanto, submeter suas atividades a mecanismos de automonitoramento e tomar medidas corretivas em casos de violações de tais direitos.

16. "(...) human rights have become part of the discourse of the private market, as well as of the state system." 
Dados publicados no 2017 United Nations Global Compact Progress Report: business solutions to sustainable development demonstram que a opção pela adoção de documentos é significativamente maior do que, por exemplo, a de mecanismos de monitoramento, denúncia e que apresentem a implementação das açóes tomadas pelas empresas, mecanismos esses adotados por apenas $29 \%$ das companhias cobertas pelo relatório (UNGC, 2017, p. 31). A porcentagem de empresas que realizam avaliaçóes de impacto ainda é baixa, sendo 58\% na área ambiental, 31\% na área laboral, 22\% em anticorrupção e apenas $15 \%$ em DHs.

Na prática, violaçôes seguem acontecendo, apesar do crescimento exponencial de mecanismos de RSC. Informações disponíveis sugerem que, de 2008 a 2014, "houve um aumento sem precedentes nas violaçóes dos DHs em todo o mundo; cerca de 70\%, de acordo com um novo relatório" (tradução nossa). ${ }^{17}$ Também alarmantes são as revelaçôes de que a exploração do trabalho forçado possa gerar lucros de US\$ 150 bilhóes por ano ${ }^{18}$ e de que $11 \%$ das empresas do Reino Unido considerem provável a utilizaçáo de trabalho escravo em suas cadeias de suprimento. Pesquisas recentes também indicam que $72 \%$ dos profissionais britânicos não sabem o que acontece em suas cadeias de suprimentos para além do segundo nível de fornecedores, e apenas $11 \%$ dizem ter visibilidade de toda a cadeia produtiva. ${ }^{19}$

Logo, o que se observa é que os sistemas voluntários não estão conseguindo coibir as violaçôes de DHs cometidas por ETNs ou limitam-se a tão somente identificar práticas contrárias a esses direitos. Por consequência, se os acordos de investimento não dispuserem de outros mecanismos que criem incentivos ao cumprimento desse tipo de cláusula, a RSC tende a ter uma função apenas exortatória. No que diz respeito ao dever das empresas, as cláusulas de RSC nos TBIs geralmente evitam, em seus textos, a linguagem de obrigação legal e utilizam a palavra should, e não must. ${ }^{20}$ Para Santoso (2017, p. 543), essa escolha de termos representa uma opção deliberada por não impor obrigaçóes legais às ETNs. No entanto, a ausência de uma obrigação legal implicitamente permite que algumas companhias violem os DHs para obter lucro, na medida em que a obrigação é apenas de cunho moral. Os TBIs, portanto, mais que apenas inserirem cláusulas de RSC: eles precisam avançar em mecanismos de monitoramento, denúncias e implementaçóes de açôes das empresas.

\subsection{O que esperar da RSC no modelo brasileiro de acordos de investimento}

Os ACFIs propostos pelo Brasil apresentam alguns elementos que os diferenciam dos TBIs tradicionais e surgem justamente em um contexto de críticas a estes. ${ }^{21}$ Para Morosini e Badin (2017, p. 222), as reivindicaçôes por reformas no regime de investimento internacional estão ligadas ao desejo de relaçôes mais equilibradas entre as partes e os atores que fazem parte e se beneficiam dos acordos. Esses autores afirmam ainda que os ACFIs, enquanto modelo proposto pelo Brasil, são motivados por

17. "(...) there has been an unprecedented rise in human rights violations globally, up $70 \%$ according to a new report. Workers' rights are seriously compromised and rural and indigenous communities are facing land grabs and forced displacement amid growing demand for low-cost labour and resources". 0 relatório mencionado na reportagem é o 2014 Human Rights Risk Atlas, publicado pela firma de consultoria de riscos Maplecroft. Disponível em: <https://bit.ly/3w6yR10>.

18. Disponível em: <https://glo.bo/3h10XXx>.

19. Disponível em: <https://bit.ly/3quzXD5>.

20. Exemplos de tal disposição de RSC podem ser encontrados no art. 16 do Acordo de Investimento Bilateral Benin-Canadá, de 2013, e no art. 12 do Acordo de Investimento Bilateral Argentina-Catar, de 2012.

21. Entre as críticas, citam-se: restrições à liberdade regulatória e à capacidade dos Estados de adotarem políticas públicas; tratamento mais favorável do investidor estrangeiro em relação ao investidor nacional; elevado custo econômico e político dos procedimentos arbitrais; imposição de onerosas indenizações; e falta de transparência das decisões arbitrais. Disponível em: <https://bit.ly/3y5CLZJ>. 
esse desejo de reforma, o que levou as autoridades brasileiras a revisar regras antigas, incluir novas e até mesmo excluir outras que eram entendidas como contrárias ao status de país em desenvolvimento, como o do Brasil. Diante dessas mudanças, analisamos se o modelo brasileiro oferece avanços quanto à responsabilidade das empresas.

Por trás desse modelo de acordo, encontram-se os seguintes fundamentos: ação diplomática, respeito à legislaçáo interna e obrigaçóes mais equilibradas entre investidores nacionais e estrangeiros, bem como entre o investidor e o Estado anfitrião (Morosini e Badin, 2017, p. 224). Outro aspecto importante é a possibilidade de criar um espaço para o diálogo com a sociedade, que já aparece de forma institucionalizada nos ACFIs brasileiros em um dos seus pilares - agendas temáticas para cooperação e facilitação dos investimentos.

Entre outras regras, tal pilar prevê a elaboração de uma agenda temática entre as partes. Essas agendas são construídas bilateralmente e podem variar de acordo com o parceiro de investimento, dependendo de suas prioridades políticas e do perfil do investidor. Hoje elas incluem, por exemplo, programas envolvendo transferência de tecnologia (Morosini e Badin, 2017, p. 224-225).

O modelo de ACFI incentiva as partes a negociar compromissos especiais, cronogramas adicionais e outros acordos suplementares como segmento do acordo principal, a fim de expandir ou detalhar as agendas temáticas, ou seja, esse espaço poderia ser uma oportunidade para incluir uma agenda de DHs mais ampla nesses acordos. A inserçáo dessa agenda, porém, depende da negociação entre as partes envolvidas.

Outro aspecto relevante refere-se à utilização da cláusula de arbitragem como procedimento de solução de controvérsias. A cláusula de arbitragem nos TBIs recebe crescentes críticas, pois permite aos investidores estrangeiros evitar os órgãos administrativos e tribunais locais (Morosini e Badin, 2017, p. 1), enquanto os impactados pelo investimento não têm jurisdição, a não ser perante a justiça interna do Estado hospedeiro (Bernaz, 2017, p. 138-139).

Dito isso, a forma como a arbitragem hoje está estruturada constitui um sério obstáculo à proteção de DHs, pois: i) as violaçôes são perpetradas no Estado hospedeiro, mas este não pode propor reclamação; ii) em muitos casos, as empresas são cúmplices de violaçóes, e não o principal violador de DHs, ou, ainda, os Estados são coniventes com essas violaçóes; e iii) mesmo que existam cláusulas de RSC ou proteção de DHs nos TBIs, elas estão excluídas da arbitragem.

Os ACFIs têm buscado instituir mecanismos alternativos de solução de controvérsias e não permitem que investidores iniciem diretamente um procedimento arbitral contra os Estados. A ideia é implementar um modelo baseado em consulta, negociaçóes e mediação. Representantes do governo brasileiro sublinham que, ainda que haja previsão de arbitragem Estado-Estado nos acordos, ela não deve ser o principal mecanismo para a solução de disputas (Morosini e Badin, 2016). Somente se o comitê conjunto não for capaz de elaborar uma solução mutuamente satisfatória, o Estado da parte afetada poderá apresentar à outra parte um pedido por escrito para o estabelecimento de um tribunal arbitral. Em outras palavras, o comitê conjunto é uma etapa obrigatória antes do procedimento arbitral (Morosini e Badin, 2017, p. 234). Com relação a esse comitê, entre suas atribuiçóes está a de monitorar a implementação e a execução do acordo. Não só isso, ele pode convidar o setor privado e a sociedade civil a integrá-lo, quando aplicável (op. cit., p. 226). 
Em 2019, o Brasil instituiu o Ombudsman de Investimentos Diretos (OID), ${ }^{22}$ cujo ponto focal, papel que é exercido pela Secretaria Executiva da Câmara de Comércio Exterior (Camex), deve dar assistência e orientação tanto aos investidores externos no Brasil quanto aos brasileiros em relação aos seus investimentos no exterior. O OID também pode apresentar soluçóes para questionamentos e dar seguimento a demandas dos investidores, em especial nos países com os quais o Brasil tenha acordo de investimento em vigor. ${ }^{23}$ Tanto o ponto focal quanto o comitê conjunto têm a finalidade de promover o intercâmbio de informação entre as partes e, em caso de controvérsia, implementar mecanismos de consultas, negociaçôes e mediação (Morosini e Badin, 2017, p. 227).

Destaca-se ainda que, conjuntamente ao OID, foi lançado o novo modelo do Ponto de Contato Nacional (PCN) da OCDE para empresas multinacionais operando no Brasil. O PCN atua como um fórum no qual interessados podem apresentar reclamaçóes contra multinacionais de países aderentes que supostamente descumpriram preceitos das diretrizes da OCDE. ${ }^{24} \mathrm{O}$ Brasil possui uma lista de reclamaçôes nesse âmbito. ${ }^{25}$

O modelo brasileiro de acordos de investimento possui um anexo definindo princípios e padróes de RSC, com o objetivo de incentivar os investidores estrangeiros a respeitar os $\mathrm{DHs}$ e as leis ambientais no país anfitrião. Cabe destacar que o rol de princípios e padróes tende a ser mais amplo do que em TBIs tradicionais. Todos os acordos assinados pelo Brasil seguindo esse modelo contêm cláusulas como respeitar a proteção do meio ambiente e o desenvolvimento sustentável; respeitar os direitos humanos daqueles envolvidos nas atividades dessas empresas; estimular a cooperação com comunidades locais; abster-se de ingerência indevida nas atividades políticas locais; e apoiar e manter princípios de boa governança. ${ }^{26}$

O modelo brasileiro ainda avança no sentido de que as questóes envolvendo RSC podem ser levadas ao comitê conjunto e ao ponto focal, que são estruturas importantes de monitoramento e gestáo criadas pelos ACFIs. Contudo, embora a inclusão de cláusulas de RSC mais amplas no modelo brasileiro pareça expandir e criar um novo mecanismo de proteçáo aos DHs e de responsabilização das empresas, estas seguem tendo como base uma proteçáo legal de soft law, ou seja, voluntária; e, embora questóes de RSC possam ser levadas a essas estruturas internas previstas no acordo, elas continuam excluídas da arbitragem.

Não se pode ignorar que economias como a brasileira, que dependem significativamente do capital estrangeiro, tendem a adotar políticas favoráveis para atrair investimentos, o que pode significar colocar as preocupaçóes com os $\mathrm{DH}$ em segundo plano. Em cenários como esse, existe uma preocupaçáo de que as violaçóes de $\mathrm{DH}$ acabem por não ter os encaminhamentos desejados nos procedimentos levados a cabo nos referidos órgãos presentes nos ACFIs. Ademais, entende-se que a lógica adotada nos ACFIs incorre no risco de que instrumentos de RSC passem a ser vistos como uma solução para os abusos sistêmicos dos $\mathrm{DH}$ e acabem contribuindo para um afastamento de medidas mais eficazes. Visando ampliar a efetividade dos ACFIs enquanto instrumentos equilibrados que promovam o investimento estrangeiro ao mesmo tempo que salvaguardem as comunidades impactadas, pode-se

\footnotetext{
22. Disponível em: <https://bit.ly/3qv96GV>.

23. Disponível em: <https://bit.ly/3qv96GV>.

24. Disponível em: <https://bit.ly/3gsXH5Q>.

25. Disponivel em: <http://mneguidelines.oecd.org/database/>

26. Disponível em: <https://bit.ly/3y5CLZJ>.
} 
pensar em algumas alternativas factíveis. Primeiramente, vincular as cláusulas de RSC dos acordos a tratados com força obrigatória de $\mathrm{DHs}$ ratificados pelo Brasil. Em adição, sugere-se que tais cláusulas também incorporem linguagem relativa ao direito costumeiro internacional. Assim, durante o exercício de interpretação do julgador acerca da RSC, este poderá ampliar a margem de proteção de DHs pela via do costume internacional.

Em matéria de procedimentos, sugere-se que as cláusulas de RSC também sujeitem-se ao mecanismo de solução de controvérsias Estado-Estado. Dessa forma, o compromisso de assegurar o cumprimento das cláusulas de RSC não ficaria apenas a cargo do ombudsman e do comitê conjunto. Haveria, assim, a possibilidade de que tribunais arbitrais pudessem adjudicar essas cláusulas, vinculando os Estados a obrigaçóes de DHs, ainda mais se as cláusulas de RSC incorporarem linguagem de direito internacional vinculante.

\section{PROPOSTAS PARA INSTRUMENTALIZAR AS OBRIGAÇÕES DAS ETNs PARA ALÉM DA RSC}

A partir da análise anterior, conclui-se que a RSC não deixa de ser um instrumento importante no sentido de reconhecer que as ETNs, em sua atuação, têm obrigações com os DHs. A RSC, porém, está construída dentro de uma lógica neoliberal, que tem limitaçôes. Essas limitaçôes encontram-se na ideia de que uma regulação vinculante que responsabilize as empresas comprometeria a liberdade de mercado e a busca por vantagens competitivas. Como consequência, a autorregulação apresenta-se como uma alternativa à responsabilidade das empresas, eximindo o direito internacional de formular normas de hard law.

A inserção da RSC nos acordos de investimento representa uma fusão entre o voluntarismo das empresas e o quadro regulatório de normas de soft law existente, a exemplo das normas da OCDE. Contudo, a simples unificação desses marcos não produz mudanças efetivas. No caso dos acordos de investimento, ambos os modelos não criam obrigaçóes diretas para o investidor, de modo que o sistema continua centralizado no Estado. Logo, cabe a este o dever de proteger os DHs, e, para tanto, deve estabelecer marcos regulatórios para as ETNs e garantir às vítimas de violação acesso à justiça e a mecanismos de reparação.

Romper com essa assimetria normativa, em que o investidor tem seus direitos assegurados e a proteção dos DHs está relegada ao soft law, exige defender que as normas relativas às empresas e aos DHs tenham, pelo menos, a mesma força que as normas de proteção aos investimentos. Por isso, é fundamental procurar estabelecer um marco regulatório que abranja a atividade das ETNs.

Uma das iniciativas que visam suprir as lacunas existentes no atual sistema é a proposta de um marco internacional legalmente vinculante. Em 2014, foi criado um grupo de trabalho na ONU para elaborar um tratado internacional sobre empresas e $\mathrm{DHs} .{ }^{27} \mathrm{O}$ draft zero para negociação de um tratado internacional sobre DHs e empresas foi apresentado em $2018^{28}$ e, em 2020, foi publicado o segundo draft, revisado do tratado vinculante. ${ }^{29}$ São majoritariamente dois os objetivos do instrumento:

27. A Resolução no 26/9, Elaboration of an international legally binding instrument on transnational corporations and other business enterprises with respect to human rights, define a criação de um grupo de trabalho para estabelecer normas vinculantes sobre empresas e DHs (OHCHR, 2014a).

28. Para uma análise do draft zero, ver OHCHR (2018), Guamán (2018) e Deva (2014).

29. Sobre o segundo draft do tratado internacional sobre empresas e DHs, checar OHCHR (2020). 
i) suprir uma lacuna existente no sentido de definir quais são as obrigações de DHs das ETNs; e ii) criar remédios efetivos em caso de violação desses direitos, sendo esse o tópico mais crucial, uma vez que não há nenhum instrumento hoje que inclua algum mecanismo vinculante de responsabilização. ${ }^{30}$

Muitas questóes foram abordadas durante as sessóes do grupo de trabalho intergovernamental aberto sobre ETNs e sobre outras empresas no âmbito dos DHs que levaram à elaboração do draft zero, ${ }^{31}$ porém destacam-se as seguintes questôes controversas:

- a definição das obrigaçóes das empresas sob o direito internacional;

- o escopo proposto de um instrumento vinculante sobre empresas e DHs; e

- o estabelecimento de mecanismos efetivos de responsabilização das ETNs e da obrigação extraterritorial dos Estados de proteger os DHs.

Contudo, o draft zero não deu respostas a esses anseios, e as controvérsias em torno dos pontos mencionados continuam a permear o debate, à medida que se avança na elaboração do texto do tratado. Cabe ressaltar, contudo, que os países considerados desenvolvidos ${ }^{32}$ (União Europeia, Estados Unidos, Japão, Reino Unido, entre outros) seguem relutantes com relação a esse instrumento e, portanto, têm se posicionado de maneira a defender os instrumentos já existentes, como os Princípios Orientadores da ONU. Tal posicionamento reforça a necessidade de um tratado internacional sobre DHs e empresas como forma de avanço no campo da responsabilidade das ETNs, preenchendo a lacuna existente: a ausência de uma norma vinculante, que crie obrigaçóes para as empresas e que promova um ambiente mais igualitário entre os países.

Ao mesmo tempo, sem desconsiderar a proposta do tratado, outras iniciativas poderiam ser levadas em consideração em outras frentes. Defende-se que reconhecer a responsabilidade extraterritorial das empresas-mães seria um dos maiores avanços na relação entre empresas e DHs. A despeito da forma transnacional com que as empresas atuam, a responsabilidade destas é limitada, uma vez que cada entidade é compreendida de maneira separada do seu Estado de incorporação (Muchlisnki, 2010), isto é, o Estado da empresa-mãe não tem jurisdição para julgar casos de violação de DHs cometidos pelas subsidiárias.

Assim, segundo Santoso (2017, p. 535), há um abuso da forma corporativa, pois os grupos corporativos apropriam-se da doutrina e criam, portanto, um véu de proteção ao estabelecer subsidiárias para facilitar ou gerir investimento, comércio e futuros riscos legais. Portanto, "quando as empresas controladoras, exercendo o controle de fato ou de direito sobre as atividades das suas subsidiárias facilitam, permitem, se beneficiam ou negligentemente não conseguem impedir violaçôes de $\mathrm{DHs}$, a forma corporativa é utilizada para imunizar as empresas-mãe de responsabilidade" (Santoso, 2017, p. 535, tradução nossa).

Como explica Muchlinski (2010), a interposição de uma entidade legal entre as vítimas e as empresas que, de fato, são as controladoras do grupo tem o objetivo de evitar que a responsabilização seja alcançada pelas vítimas, ou seja, constata-se que a forma como o sistema hoje está estruturado

30. Para uma análise sobre a pertinência da elaboração de um instrumento internacional vinculante, consultar Roland et al. (2018).

31. Sobre as sessões do grupo de trabalho intergovernamental aberto sobre empresas transnacionais, ver OHCHR (2014b).

32. Sobre o posicionamento, especialmente da União Europeia, acerca do tratado, checar OHCHR (2018). 
prevê, acima de tudo, que as ETNs são sujeitas de direito interno do Estado onde operam. ${ }^{33}$ Uma vez estabelecida em determinado território, a empresa se vincula a determinada jurisdição. Ocorre que justamente essa limitação faz com que, muitas vezes, as empresas, visando à redução de custos e ao aumento dos lucros, busquem países com baixa proteção de $\mathrm{DHs}$ para lá se estabelecerem, o que também facilita a impunidade.

A fim de solucionar o problema, uma cláusula de extraterritorialidade poderia ser adotada em instrumentos como os TBIs. ${ }^{34}$ Tal cláusula efetivamente incorporaria mais obrigaçôes aos investidores, a fim de incentivá-los a respeitar os DHs e as leis ambientais no Estado anfitrião, dado que isso romperia com a barreira existente para açóes judiciais contra as ETNs em seus países de origem.

Além disso, a incorporação dessa cláusula nos ACFIs seria um grande avanço, enquanto modelo advindo de um país em desenvolvimento, onde o ingresso de investimento é significativamente maior que a saída. Tal cláusula, além de impor obrigações legais diretas às empresas, estenderia as obrigaçóes de regular e controlar os atores privados sob a jurisdiçáo do Estado hospedeiro ao Estado de origem do investimento. Adicionalmente, romperia com a lógica tradicional dos TBIs, que é a de proteger exclusivamente o investidor. Por fim, outro avanço nesse sentido seria exigir dos Estados signatários que incorporem em sua legislação nacional normas acerca do levantamento do véu corporativo, visando à proteção de $\mathrm{DHs}$, especialmente no âmbito do direito empresarial.

\section{CONSIDERAÇÕES FINAIS}

Neste artigo, evidenciou-se a relação entre a RSC e o neoliberalismo. Aquela segue a lógica deste, qual seja, a de que cabe ao Estado assegurar a liberdade de mercado, o que justificaria o estabelecimento de normas que facilitam a circulaçáo de capital. Ao mesmo tempo, a RSC assume o papel do Estado em termos de uma regulação protetiva de direitos, já que demonstra que as empresas estão comprometidas com a proteção social. Não obstante, a RSC tem o papel de demonstrar que as empresas fazem mais do que suas obrigaçôes legais, já que, efetivamente, cumprem uma obrigação legal que é mínima e adotam autorregulaçôes voluntárias que contribuem para o bem-estar coletivo. Dessa forma, a RSC estaria legitimando o Estado neoliberal e as próprias empresas.

Um número crescente de companhias tem incorporado medidas de RSC, o que reforça o discurso de que ela é benéfica à proteção dos DHs. Essa tendência acaba por se refletir nos TBIs, que têm incorporado cláusulas de RSC em seus textos. Além disso, uma crise generalizada de legitimidade com relação ao regime internacional de investimentos tem afetado os países do Norte e do Sul Global, impulsionando mudanças nesses marcos regulatórios.

Algumas consideraçôes, no entanto, precisam ser feitas. Primeiro, esse é um tema novo a ser regulado nos TBIs; as disposiçôes sobre o tema permanecem raras e, quando presentes, tendem a ser abstratas e não apresentam grandes avanços quanto à proteção dos DHs. Segundo, há um problema estrutural

33. Um caso recente é o da Kiobel v. Royal Dutch Petroleum. Em 2013, um tribunal norte-americano proferiu sua decisão em relação à alegada cumplicidade de uma corporação petrolifera estrangeira em abusos de DHs na Nigéria. Na apelação ao Second Circuit, a corporação afirmou que a empresa não poderia ser processada perante a corte norte-americana, uma vez que o direito internacional não reconhece a responsabilidade dessa empresa. 0 caso chegou até a Suprema Corte e, por fim, foi arquivado, sob o argumento de que as reclamações não tocam ou dizem respeito à jurisdição americana (Baumann-Pauly e Nolan, 2016, p. 248).

34. 0 debate acerca da desconsideração do véu corporativo vem ganhando espaço nas discussões sobre os acordos de investimento. Para tanto, ver Vastardis e Chambers (2018). 
nesse debate, que se deve ao fato de que os países onde está sediada a maioria das ETNs (e que são os proponentes desse modelo de acordo) seguem propagando um modelo neoliberal. Portanto, ao mesmo tempo que os países desenvolvidos demonstram sua preocupação com a proteção dos $\mathrm{DHs}$ ao estabelecer cláusulas de RSC, continuam a reforçar seu caráter não vinculante. Em terceiro lugar está a própria lógica da RSC, que tem sua origem e sua justificativa na redução do papel do Estado, diante de um processo de desregulaçáo, e, portanto, náo se legitima diante da própria ausência do Estado em garantir certos DHs.

Todavia, é possível avançar no marco dos TBIs e, nesse sentido, os ACFIs podem se apresentar como um novo espaço em que o investimento estrangeiro e os DHs possam dialogar de forma mais efetiva, já que os são um modelo pensado pelo Brasil, país em desenvolvimento e que busca atrair investimento estrangeiro, mas que, ao mesmo tempo, deseja assegurar sua soberania para a promoção de políticas públicas, como os DHs.

Os ACFIs apresentam, de fato, alguns avanços importantes, mas as cláusulas de RSC continuam sendo genéricas, não trazem um catálogo específico de $\mathrm{DHs}$ nem normas claras sobre quais são efetivamente as obrigaçóes das empresas para que, em caso de descumprimento, possa haver sanções adequadas. Deve-se ainda ressaltar que os ACFIs não fazem qualquer referência expressa a instrumentos internacionais relacionados à proteçáo dos $\mathrm{DH}$, além de utilizar uma linguagem de normas de soft law.

Por fim, alternativas apresentam-se como possíveis e não são excludentes. A proposta de uma cláusula de extraterritorialidade, tanto nos TBIs tradicionais quanto nos ACFIs, objetiva estimular o debate, evidenciando os limites da RSC em si e sua inserção nos TBIs, ao mesmo tempo que se compreende e se defende a necessidade de uma regulação vinculante.

\section{REFERÊNCIAS}

BACKER, L. C. Realising socio-economic rights under emerging global: regulatory frameworks: the potential impact of privatisation and the role of companies in China and India. In: DEVA, S. (Ed.). Socio economic rights in emerging free markets: comparative perspectives from India and China. London: Routledge, 2015.

BAUMANN-PAULY, D.; NOLAN, J. (Eds.). Business and human rights: from principles to practice. New York: Routledge, 2016.

BERNAZ, N. Business and human rights: history, law and policy. London: Routledge, 2017. (Bridging the Accountability Gap).

BROWN, W. Neoliberalism and the end of liberal democracy. In: Edgework: critical essays on knowledge and politics. Princeton: Princeton University Press, 2009. p. 37-59.

BUHMANN, K. The development of the 'UN framework': a pragmatic process towards a pragmatic output. In: MARES, R. (Ed.). The UN guiding principles on business and human rights: foundations and implementation. Leiden; Boston: Martinus Nijhoff, 2012.

BUSTURIA, A. A. L.-F. de. Derechos humanos, empresas transnacionales y responsabilidad social empresarial. Madrid: Instituto Berg, 2015.

CARROLL, A. B. Corporate social responsibility: evolution of a definitional construct. Business and Society, v. 38, n. 3, p. 268-295, 1999. Disponível em: <https://bit.ly/3jioQvn>. Acesso em: 10 nov. 2020.

DEVA, S. The human rights obligations of business: reimagining the treaty business. Geneva: [s.n.], 2014. Disponível em: <https://bit.ly/3hg1jZg >. Acesso em: 10 nov. 2020. 
FRIEDEN, J. A. Capitalismo global. Rio de Janeiro: Zahar, 2008.

GUAMÁN, A. El draft 0 del Binding Treaty: análisis crítico del contenido del texto y su adecuación con el objetivo de la Resolución 26/9. Cadernos de Pesquisa Homa, Juiz de Fora, v. 1, n. 6, 2018.

GUZMAN, A. T. Why LDCs sign treaties that hurt them: explaining the popularity of bilateral investment treaties. Virginia Journal of International Law, v. 38, p. 639-688, 1998.

HALL, S. The neoliberal revolution: Thatcher, Blair, Cameron - the long march of neoliberalism continues. Soundings: A Journal of Politics and Culture, 2011.

KINDERMAN, D. P. Free US up so we can be responsible! The co-evolution of corporate social responsibility and neo-liberalism in the UK, 1977-2010. Socio-Economic Review, v. 10, n. 1, p. 29-57, Jan. 2012. Disponível em: <https://ssrn.com/abstract=2213489>. Acesso em: 10 nov. 2020.

KNOX, J. H. The Ruggie rules: applying human rights law to corporations. In: MARES, R. (Ed.). The UN guiding principles on business and human rights: foundations and implementation. Leiden; Boston: Martinus Nijhoff, 2012.

LAGOUTTE, S. The UN guiding principles on business and human rights: a confusing 'smart mix' of soft and hard international human rights law. In: LAGOUTTE, S.; GAMMELTOFT-HANSEN, T.; CERONE, J. (Eds.). Tracing the roles of soft law in human rights. Oxford: Oxford Scholarship Online, 2016.

MARTÍN-ORTEGA, O. Empresas multinacionales y derechos humanos en el derecho internacional. Barcelona: Bosch, 2008.

MOROSINI, F. C.; BADIN, M. R. S. O Acordo de Cooperação e Facilitação de Investimentos: o que está por trás desta inovação regulatória? Pontes - Comércio e Desenvolvimento Sustentável, v. 12, n. 1, p. 9-12, 2016.

Reconceptualizing international investment law from Global South. FGV Direito SP Research Paper Series, n. 150, Sept. 2017. Disponível em: <https://ssrn.com/abstract=3039077>. Acesso em: 10 nov. 2020.

MUCHLISNKI, P. Limited liability and multinational enterprises: a case for reform? Cambridge Journal of Economics, v. 34, n. 5, p. 915-928, Sept. 2010.

OHCHR - OFFICE OF THE HIGH COMMISSIONER FOR HUMAN RIGHTS. Elaboration of an international legally binding instrument on transnational corporations and other business enterprises with respect to human rights. [s.l.]: OHCHR, 14 July 2014a. Disponível em: <https://bit.ly/3qDy475>.

Open-ended intergovernmental working group on transnational corporations and other business enterprises with respect to human rights. [s.l.]: OHCHR, 26 June 2014b. Disponível em: <https://bit. ly/3xfE3kM>. Acesso em: 10 nov. 2017.

Legally binding instrument to regulate, in international human rights law, the activities of transnational corporations and other business enterprises (zero draft). [s.l.]: OHCHR, 16 July 2018. Disponível em: <https://bit.ly/2SwRjT8>. Acesso em: 10 nov. 2020.

Legally binding instrument to regulate, in international human rights law, the activities of transnational corporations and other business enterprises (second draft). [s.l.]: OHCHR, 6 Aug. 2020. Disponível em: <https://bit.ly/3A6XApB>. Acesso em: 10 nov. 2020.

ROLAND, M. C. et al. Desafios e perspectivas para a construção de um instrumento jurídico vinculante em direitos humanos e empresas. Revista Direito GV, v. 14, n. 2, p. 393-417, 2018. Disponível em: <https:// bit.ly/3AgVXWD>. Acesso em: 10 fev. 2021.

SANTOSO, B. "Just business": is the current regulatory framework an adequate solution to human rights abuses by transnational corporations? German Law Journal, v. 18, n. 3, p. 533, May 2017. 
SORNARAJAH, M. The international law on foreign investment. 3rd ed. New York: Cambridge University Press, 2010.

TSUTSUI, K.; LIM, A. Corporate social responsibility in a globalizing world. Cambridge: Cambridge University Press, 2015.

UNGC - UNITED NATIONS GLOBAL COMPACT. 2017 United Nations Global Compact Progress Report: business solutions to sustainable development. [s.l.]: UNGC, 2017. Disponível em: <https://www. unglobalcompact.org/library/5431>. Acesso em: 10 nov. 2020.

VASTARDIS, Y. A.; CHAMBERS, R. Overcoming the corporate veil challenge: could investment law inspire the proposed business and human rights treaty? International and Comparative Law Quarterly, v. 67, n. 2, Apr. 2018, p. 389-423. Disponível em: <https://doi.org/10.1017/S0020589317000471>. Acesso em: 10 fev. 2021. 